\title{
Effect of routine claw trimming on claw temperature in dairy cows measured by infrared thermography
}

\author{
M. Alsaaod, ${ }^{* 1}$ C. Syring, ${ }^{*}$ M. Luternauer, ${ }^{*}$ M. G. Doherr, $\dagger$ and A. Steiner ${ }^{*}$ \\ ${ }^{*}$ Clinic for Ruminants, Vetsuisse Faculty, University of Bern, 3001 Bern, Switzerland \\ †Institute for Veterinary Epidemiology and Biostatistics, Free University, 14163 Berlin, Germany
}

\begin{abstract}
Infrared thermography (IRT) was used to assess the effect of routine claw trimming on claw temperature. In total, 648 IRT observations each were collected from 81 cows housed in 6 tiestalls before and 3 wk after claw trimming. The feet were classified as either healthy (nonlesion group, $\mathrm{n}=182$ ) or affected with infectious foot disorders (group IFD, $\mathrm{n}=142$ ). The maximal surface temperatures of the coronary band and skin and the difference of the maximal temperatures $(\Delta T)$ between the lateral and medial claws of the respective foot were assessed. Linear mixed models, correcting for the hierarchical structure of the data, ambient temperature, and infectious status of the claws, were developed to evaluate the effect of time in relation to the trimming event ( $\mathrm{d} 0$ versus d 21) and claw (medial versus lateral). Front feet and hind feet were analyzed separately. Ambient temperature and infectious foot status were identified as external and internal factors, respectively, that significantly affected claw temperature. Before claw trimming, the lateral claws of the hind feet were significantly warmer compared with the medial claws, whereas such a difference was not evident for the claws of the front feet. At d 21, $\Delta \mathrm{T}$ of the hind feet was reduced by $\geq 0.25^{\circ} \mathrm{C}$, whereas it was increased by $\leq 0.13^{\circ} \mathrm{C}$ in the front feet compared with $\mathrm{d} 0$. Therefore, trimming was associated with a remarkable decrease of $\Delta \mathrm{T}$ of the hind claws. Equalizing the weight bearing of the hind feet by routine claw trimming is associated with a measurable reduction of $\Delta \mathrm{T}$ between the paired hind claws.
\end{abstract}

Key words: infrared thermography, dairy cow, infectious claw disease, routine claw trimming

\section{INTRODUCTION}

Claw diseases are a major cause of lameness and have a multifactorial etiology; therefore, it is useful to divide disorders into 2 primary groups, infectious and non-

Received July 10, 2014.

Accepted December 19, 2014.

${ }^{1}$ Corresponding author: maher.alsaaod@vetsuisse.unibe.ch infectious foot disorders (Murray et al., 1996; Bicalho and Oikonomou, 2013).

In cattle, measuring the length of the paired digits reveals an anatomical difference between medial and lateral digits (Nacambo et al., 2007; Muggli et al., 2011). The lateral digits of the hind feet are significantly longer (overall length from epiphyseal line to the tip of distal phalanx) than the medial digits, which may be considered a risk factor for chronic overload and claw lameness (Muggli et al., 2011). In cattle, the lateral claws of the hind feet are larger and bear more weight than the medial claws (Toussaint Raven, 1989; Nuss and Paulus, 2006). Moreover, increasing pressure concentration on the corium has been attributed to damage of the dermal papillae, followed by disturbance and partial discontinuation of horn production, which increases the risk of developing sole lesions (Toussaint Raven, 1989; Blowey et al., 2000; Räber et al., 2004; Bicalho and Oikonomou, 2013). The lateral claws of the hind feet are mainly affected by such lesions (Murray et al., 1996). Sole ulcers at the Rusterholz site occur most frequently in the lateral hind claws due to excessive pressure exerted on the larger claw, which causes trauma to the corium. In contrast, in the front feet, sole ulcers occur less frequently and, when they do occur, mainly involve the medial claws (Rusterholz, 1920; Collick et al., 1989; van Amstel and Shearer, 2006).

Functional claw trimming in dairy cows is performed as a routine management procedure to prevent the development of claw disorders (Manske et al., 2002). Numerous studies have shown that prevalence of claw disorders and lameness is decreased in farms that follow a routine claw-trimming protocol (Toussaint Raven, 1989; Phillips et al., 2000; Shearer and van Amstel, 2001). Routine claw trimming is achieved by removal of excess horn material. The contact area of the claws with the hard surface is increased and the weight-bearing balance between the medial and lateral claw of the foot is improved, with a partial shift from the lateral to the medial claw in the hind feet (Toussaint Raven, 1989; van der Tol et al., 2004; Carvalho et al., 2006). Several studies have reported a significant effect of routine claw trimming on biomechanical properties of the 
bovine foot (van der Tol et al., 2002, 2004; Carvalho et al., 2006; Meyer et al., 2007). Measurements of ground reaction forces during standing showed that the lateral claws of the hind feet and the medial claws of the front feet are exposed to higher maximal pressures compared with the respective partner claws (van der Tol et al., 2002). Weight-bearing area and pressure distribution of the solar surface of the claw are mainly affected by abrasiveness of the flooring systems. Telezhenko et al. (2008) stated that on rough floors, such as asphalt, the sole zone plays a main role in weight bearing (although pressure is lesser due to the increased contact area of the sole), whereas in floors with low abrasion such as rubber mats, the contact area of the claw and the floor is reduced, involving mainly the bulbar and wall segments, which results in greater average contact pressure exerted on the claws. Increasing mechanical pressure over the metatarsal heads, great toe, and heel has been associated with elevated surface temperature of the respective region in humans (Goller et al., 1971, Chan et al., 1991).

Infrared thermography (IRT) provides a noninvasive and rapid tool to measure heat emitted by the skin as an infrared pictorial representation (Pringle et al., 1998; Eddy et al., 2001; Van Hoogmoed and Snyder, 2002). The local skin surface temperature is increased in cases of elevated metabolic activity (Stewart et al., 2007) or inflammatory conditions (Van Hoogmoed and Snyder, 2002; Alsaaod et al., 2014). In horses, an even thermal pattern of the hoof was found when weight bearing within the hoof was balanced, and the thermal bands were unilaterally enlarged at the site of increased pressure in unbalanced hooves (www.veterinary-thermalimaging.com). Infrared thermography allows detection of digital dermatitis (DD) lesions of dairy cows with a sensitivity of $89.1 \%$ and a specificity of $66.6 \%$ (Alsaaod et al., 2014). In healthy feet, the surface temperature of the lateral hind claw is significantly higher than that of the partner claw (Wilhelm, 2010).

We hypothesized that the difference in superficial temperatures between the medial and lateral claws of the hind feet would be decreased by routine claw trimming. This would, in turn, make visible the purpose of routine foot trimming (temporary shift of weight bearing from the lateral to the medial claw), using IRT. This might allow for objective, automated, and noninvasive assessment of the success of the professional activity of foot-trimmers.

\section{MATERIALS AND METHODS}

\section{Farms and Cows}

This study was carried out under field conditions in March and April 2013. Eighty-one dairy cows housed in 6 tiestalls were used. All cows were kept on various types of rubber mats covered with straw bedding and had access to an outside exercise pen at least every 2 wk during the winter season and access to a pasture at least twice a week during the summer season. The thickness of rubber mats varied from 20 to $30 \mathrm{~mm}$. The elasticity of the rubber mats was not measured on-farm. All mats had a surface with a hammer-beat structure to enhance grip and an underside profile with rubber knobs to allow for maximum elasticity (Platz et al., 2007). None of the cows was allowed access to pasture or the outside pen within $48 \mathrm{~h}$ preceding the claw temperature measurement. The farms were selected by convenience sampling among herds that participated in the routine herd health service offered by the Clinic for Ruminants, Vetsuisse-Faculty (University of Berne, Switzerland). In each farm, claw trimming was performed according to a standardized protocol by an individual separate professional claw trimmer, using an angle grinder (Lischer et al., 2014). All front and hind feet were trimmed. Infectious foot disorders (IFD) were treated by the claw trimmer according to standardized procedures: DD by administration of Intra Hoof-fit Gel (IntraCare BV, Haaften, the Netherlands), interdigital phlegmona by topical administration of chlortetracycline spray, and heel horn erosion (HHE) by pasting wood tar on the affected horn. The frequency of claw trimming on the selected farms ranged from 1 to 3 times per year, with one of the sessions performed in spring. The mean age of the cows was $4.9 \mathrm{yr}$ (range: 2-15 yr). The breeds involved were Holstein Friesian (n $=12 ; 14.8 \%)$, Red Holstein $(\mathrm{n}=12 ; 14.8 \%)$, and Swiss Fleckvieh $(\mathrm{n}=57 ; 70.4 \%)$. The mean number of cows per farm was 14 (range: 10-17). Median 305-d milk yield was 8,354 L (range: 7,056-9,037 L) and median DIM for experimental lactating cows was $160 \mathrm{~d}$ (range: $8-526 \mathrm{~d})$.

\section{Clinical Diagnosis and Classification of Claw Lesions}

At claw trimming, all foot lesion data were documented by 1 of 2 trained veterinarians, using the claw data analysis software Klauenmanager, version 3.1 (SEG Informationstechnik, Bad Ischl, Austria; Kofler, 2013). To optimize interobserver concordance, the 2 veterinarians were trained in defining claw lesions and claw lesion severity (slight, moderate, severe) scoring with pictures at repeated training sessions held before the start of the study.

The feet were classified as either healthy (nonlesion group, $\mathrm{n}=182)$ or affected with IFD $(\mathrm{n}=142)$. The IFD group included feet with moderate and severe HHE $(\mathrm{n}=104)$, DD (M1 to M4, as described by Döpfer 
et al., $1997 ; \mathrm{n}=77)$, interdigital phlegmona $(\mathrm{n}=1)$, or a combination of these lesions. Noninfectious lesions included white line disease $(\mathrm{n}=29)$, double sole $(\mathrm{n}=$ $13)$, and sole ulcer $(\mathrm{n}=3)$. All noninfectious lesions were superficial, had a severity score of "slight" and were completely removed by functional claw trimming. These feet $(\mathrm{n}=42)$ were, therefore, classified as healthy.

\section{IRT Imaging}

Thermographic images were obtained using the Ti25 Thermal Imager (Fluke IR-Fusion Technology, Everett, WA; emissivity value was set at 0.95 with a precision of $\pm 0.01^{\circ} \mathrm{C}$ ) to assess the maximal surface temperatures $(\mathbf{m a x})$ of the coronary band $(\mathbf{C B})$ and skin $(\mathbf{S})$ and the temperature difference $(\Delta \mathbf{T})$ between lateral and medial claws of the respective foot. The procedures of thermographic scanning were the same as described previously (Alsaaod et al., 2014). Briefly, all cows were scanned from the lateral and medial aspects while standing on plain rubber mats in their respective tiestall partitions, and all scans were done at the same distance $(0.5 \mathrm{~m})$. The claws were scanned without any previous washing; dirty feet ( $\mathrm{n}=6$ cows) were not included in the study because humidity and dirt may influence the surface temperature (Wilhelm, 2010). Images were analyzed using the software SmartView 3.1.82.0 (Fluke IR-Fusion Technology). The areas of the CB (area 1 $=$ junction between the skin and the horn of the claw) and of S (area 2 = neighboring the CB area proximally) were selected with the help of the same software tool (Figure 1). A data logger was located in the center of the barn to measure the ambient temperature during each sample collection session. All measurements were done in closed barns without exposure to any direct sunlight or detectable airflow. Thermography of the claws of each cow was performed immediately before routine foot trimming (d 0) and 3 wk later (d 21). At the $\mathrm{d} 21$ imaging, the cows were screened for the presence of clinical lameness in the standing animal; at that time, individual inspection of the claws in a trimming chute was not undertaken.

\section{Data Analysis and Statistics}

Measurements were described using standard measures of central tendency and spread. Partial correlation coefficients were used to assess the strength of the numerical relationship between ambient temperature and claw temperature, controlled for the effect of infectious status $(0,1)$. The difference in temperature between the lateral and medial claws of each foot $(\Delta \mathrm{T})$ was calculated separately for the 2 locations $\left[\left(\mathrm{CB}_{\max }\right.\right.$ medial $-\mathrm{CB}_{\max }$ lateral); $\left(\mathrm{S}_{\max }\right.$ medial $-\mathrm{S}_{\max }$ lateral $\left.)\right]$ and used as the dependent variable in the linear mixed models (STATA 12 module xtmixed; StataCorp LP, College Station, TX; www.stata.com). These models were adjusted for the hierarchical structure of the data (cows within farms) by including random effects of farm and cow, and for the ambient temperature and infectious status of the claws (included as fixed effects), and evaluated the effect of treatment (the trimming event; d 0 versus $\mathrm{d} 21$ ) on $\Delta \mathrm{T}$.

Within the respective models, outcomes were checked for normality using visual means such as histograms and quantile-quantile plots. Given the reasonably large number of observations in the model, the data were considered sufficiently close to normality with no severe outliers.

Front feet and hind feet were analyzed separately. An attempt was made to include the foot (left, right) as a random or fixed effect into the model; however, these models did not converge (details not shown). The threshold level for statistical significance was set to $\alpha$ $=0.05$, and $P$-values $<0.1$ were interpreted as trends.

\section{RESULTS}

The mean ambient temperature on $\mathrm{d} 0$ and $\mathrm{d} 21$ inside the barns was $14.0^{\circ} \mathrm{C}$ (range: 8.3 to $20.1^{\circ} \mathrm{C}$ ). The maximal temperatures at regions $\mathrm{CB}$ and $\mathrm{S}$ were significantly affected by ambient temperature before and after claw trimming $(P<0.001)$. Increased ambient temperature was associated with higher $\mathrm{CB}_{\max }$ and $\mathrm{S}_{\max }$. The pairwise correlation coefficients of all comparisons between claw temperature (various measuring points) and ambient temperature ranged between 0.25 and 0.5 , indicating a weak to moderate linear numerical association and thus relevant to correct for the effect of ambient temperature in the respective regression models.

Infection status had a significant effect at the front and hind feet levels on $\mathrm{CB}_{\max }(P=0.027, P=0.046)$ and on $\mathrm{S}_{\max }(P=0.015, P=0.002)$ before the clawtrimming event: IFD were associated with higher $\mathrm{CB}_{\max }$ and $\mathrm{S}_{\max }$. This effect disappeared after the claw-trimming event except for $S_{\max }$ of the front feet $(P=0.031$; Table 1).

\section{Claw Temperature at Hind Feet Level}

Before claw trimming, $\mathrm{CB}_{\max }\left(\Delta \mathrm{T}=-0.73 \pm 0.09^{\circ} \mathrm{C}\right)$ and $S_{\max }\left(\Delta \mathrm{T}=-0.41 \pm 0.12^{\circ} \mathrm{C}\right)$ of the lateral claws of the hind feet were significantly higher compared with those of the medial claws $(P<0.001)$. After claw trimming, $\mathrm{CB}_{\max }$ of the lateral claw $\left(\Delta \mathrm{T}=-0.48 \pm 0.08^{\circ} \mathrm{C}\right)$ was still significantly higher than that of the medial claw $(P<0.001)$, whereas we detected no difference in 

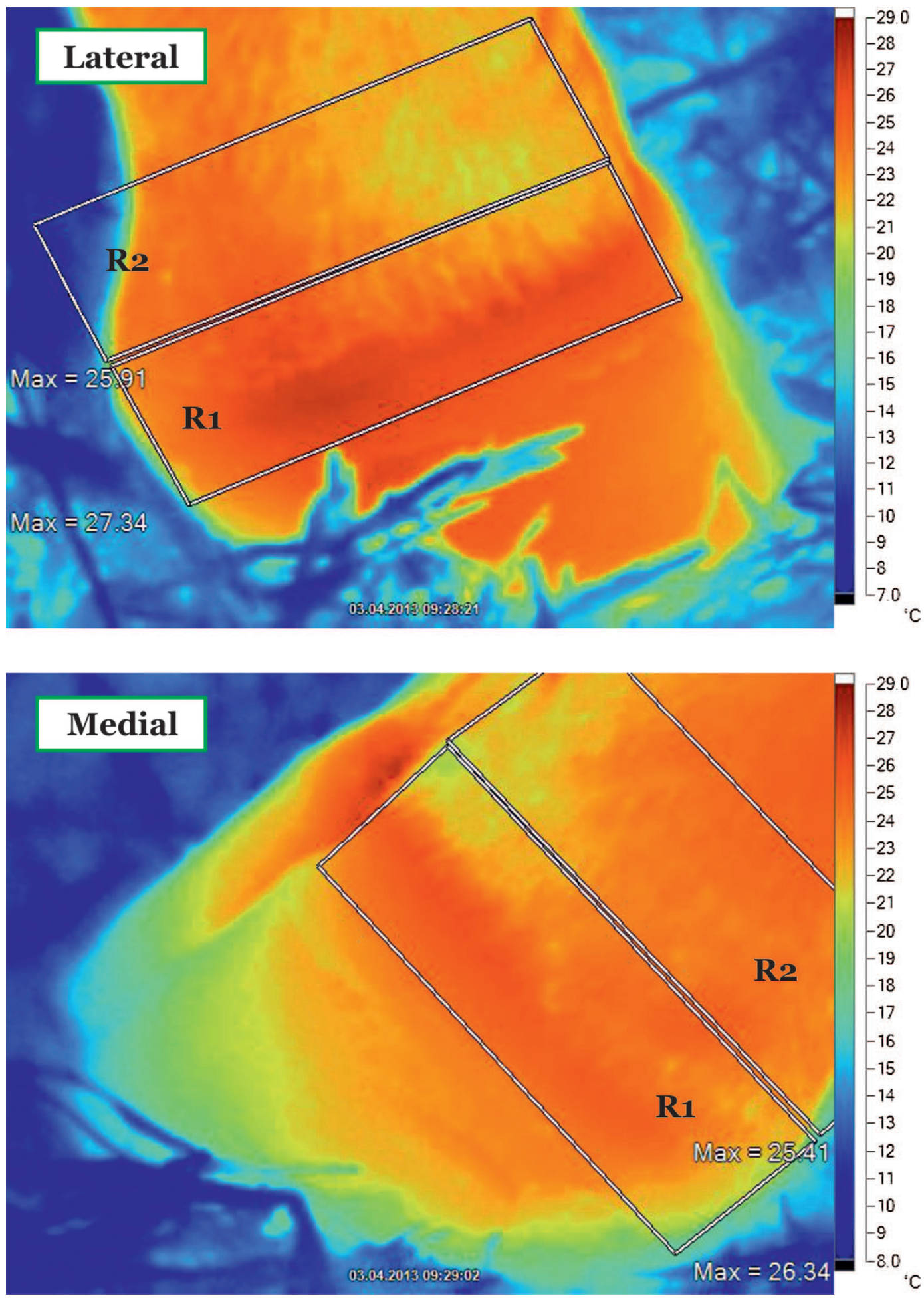

Figure 1. Infrared thermography images of the right hind foot of a 3-yr-old cow (lateral and medial aspects). Two areas are defined by the thermographic software: $\mathrm{R} 1=$ coronary band region $(\mathrm{CB}$; junction between the skin and the horn of the claw) and $\mathrm{R} 2=$ skin region $(\mathrm{S}$; neighboring the $\mathrm{CB}$ area proximally). Color version available online. 
Table 1. Model estimates (regression coefficients and standard errors) for the difference of maximal temperature $\left(\Delta \mathrm{T}\right.$, $\left.{ }^{\circ} \mathrm{C}\right)$ between lateral and medial claws of the coronary band $\left(\mathrm{CB}_{\max }\right)$ and skin $\left(\mathrm{S}_{\max }\right)$ region of hind and front feet before $(\mathrm{d} 0)$ and after trimming (d 21) corrected for status of infectious foot disorders (IFD) and ambient temperature

\begin{tabular}{|c|c|c|c|c|c|c|c|c|}
\hline Location/Item & \multicolumn{4}{|c|}{ Hind feet $(\mathrm{n}=162)$} & \multicolumn{4}{|c|}{ Front feet $(\mathrm{n}=162)$} \\
\hline \multicolumn{9}{|l|}{$\mathrm{CB}_{\max }$} \\
\hline$\Delta \mathrm{T}^{2}$ & $-0.73 \pm 0.09$ & $<0.001$ & $-0.48 \pm 0.076$ & $<0.001$ & $-0.10 \pm 0.09$ & 0.308 & $-0.23 \pm 0.08$ & 0.006 \\
\hline IFD status $^{3}$ & $0.41 \pm 0.2$ & 0.046 & $0.14 \pm 0.17$ & 0.395 & $0.63 \pm 0.28$ & 0.027 & $0.35 \pm 0.25$ & 0.159 \\
\hline$\Delta \mathrm{T}$ & $-0.41 \pm 0.12$ & $<0.001$ & $-0.08 \pm 0.10$ & 0.404 & $-0.08 \pm 0.10$ & 0.456 & $-0.003 \pm 0.09$ & 0.971 \\
\hline IFD status & $0.67 \pm 0.22$ & 0.002 & $0.12 \pm 0.18$ & 0.481 & $0.68 \pm 0.28$ & 0.015 & $0.52 \pm 0.24$ & 0.031 \\
\hline Ambient temperature & $0.12 \pm 0.22$ & 0.565 & $0.24 \pm 0.16$ & 0.130 & $0.06 \pm 0.34$ & 0.860 & $0.19 \pm 0.2$ & 0.347 \\
\hline
\end{tabular}

${ }^{1}$ Coeff. = multivariable linear regression parameter estimate.

${ }^{2}$ Basic $\Delta \mathrm{T}$ (baseline); a negative value indicates that the temperature of the medial claw was lower than that of the lateral claw; $\mathrm{d} 0$ and $\mathrm{d} 21$ were analyzed separately.

${ }^{3}$ IFD status $=$ effect of change from no lesions to IFD on $\Delta \mathrm{T} ; \mathrm{d} 0$ and $\mathrm{d} 21$ were analyzed separately.

${ }^{4}$ Ambient temperature $=$ effect of ambient temperature on $\Delta \mathrm{T} ; \mathrm{d} 0$ and $\mathrm{d} 21$ were analyzed separately.

$\mathrm{S}_{\max }$ between lateral and medial claws $\left(-0.08 \pm 0.10^{\circ} \mathrm{C}\right.$; $P=0.40$; Table 1$)$. Comparison of the $\Delta \mathrm{T}$ values revealed a trend for a decrease over time of $\mathrm{CB}_{\max }(P=$ $0.081)$ and of $\mathrm{S}_{\max }(P=0.099)$. The mean $\Delta \mathrm{T}$ in the hind feet for $\mathrm{CB}_{\max }$ and $\mathrm{S}_{\max }$ was $\geq 0.25^{\circ} \mathrm{C}$. Reduction of $\Delta \mathrm{T}$ was caused by a nonsignificant decrease of both $\mathrm{CB}_{\max }$ and $\mathrm{S}_{\max }$ of the lateral claws and a concurrent nonsignificant increase of $\mathrm{CB}_{\max }$ and $\mathrm{S}_{\max }$ of the medial claws (Table 2).

\section{Claw Temperature at Front Feet Level}

Before claw trimming, $\mathrm{CB}_{\max }\left(\Delta \mathrm{T}=-0.10 \pm 0.09^{\circ} \mathrm{C}\right)$ and $\mathrm{S}_{\max }\left(\Delta \mathrm{T}=-0.08 \pm 0.10^{\circ} \mathrm{C}\right)$ of the lateral claws were not significantly different from those of the medial claws $(P=0.308, P=0.456)$. After claw trimming, $\mathrm{CB}_{\max }$ of the lateral claws $\left(\Delta \mathrm{T}=-0.23 \pm 0.08^{\circ} \mathrm{C}\right)$ was significantly higher than that of the medial claws $(P$ $=0.006)$. This was caused by a significant increase of $\mathrm{CB}_{\max }$ of the lateral claw $\left(0.75 \pm 0.34^{\circ} \mathrm{C} ; P=0.027\right)$ and a nonsignificant increase of $\mathrm{CB}_{\max }$ of the medial claw $\left(0.47 \pm 0.35^{\circ} \mathrm{C} ; P=0.17\right)$. Such a difference was not evident for $\mathrm{S}_{\max }$ between lateral and medial claws $\left(\Delta \mathrm{T}=-0.003 \pm 0.09^{\circ} \mathrm{C} ; P=0.971\right.$; Table 1$)$. Comparison of the $\Delta \mathrm{T}$ values of $\mathrm{d} 0$ compared with $\mathrm{d} 21$ did not reveal any effect of claw trimming on $\mathrm{CB}_{\max }(P=0.23)$ or $\mathrm{S}_{\max }(P=0.889)$. The mean $\Delta \mathrm{T}$ in the front feet for $\mathrm{CB}_{\max }$ and $\mathrm{S}_{\max }$ was $\leq 0.13^{\circ} \mathrm{C}$.

Table 2. Model estimates (regression coefficients and standard errors) for the difference of maximal temperature $\left({ }^{\circ} \mathrm{C}\right)$ before $(\mathrm{d} 0)$ and after $(\mathrm{d}$ 21) trimming for (a) lateral and (b) medial claws at the area of the coronary band $\left(\mathrm{CB}_{\max }\right)$ and the skin $\left(\mathrm{S}_{\max }\right)$ of hind and front feet corrected for status of infectious foot disorders (IFD) and ambient temperature

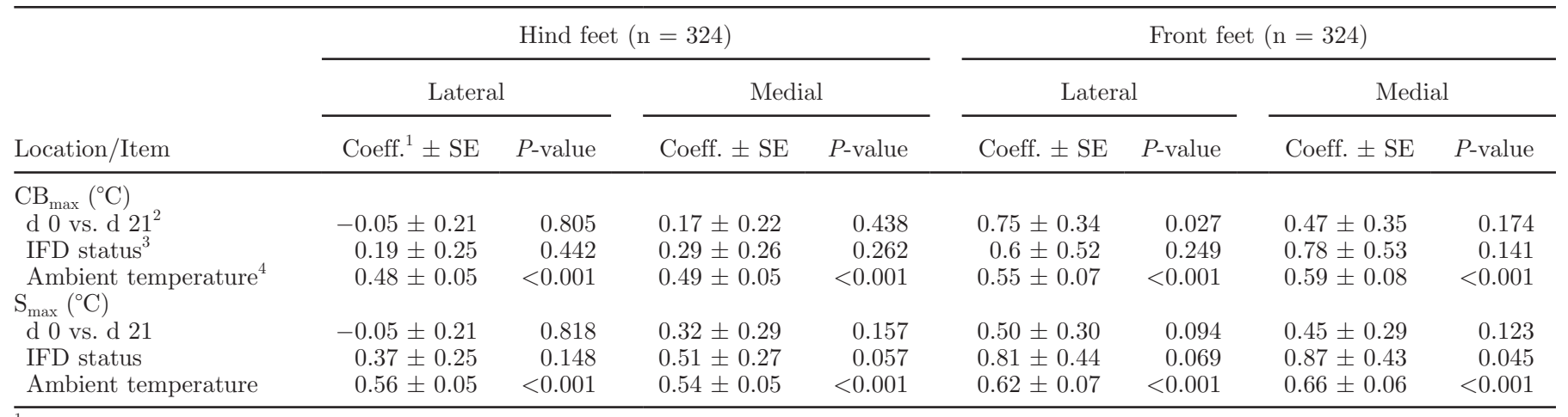

${ }^{1}$ Coeff. = multivariable linear regression parameter estimate.

${ }^{2}$ Basic temperature difference of the respective claw between d 0 and 21; a negative values indicates a lower temperature on $\mathrm{d} 0$ compared with d 21.

${ }^{3}$ Effect of change from no lesion to IFD status on temperature difference between d 0 and 21 of the respective claw.

${ }^{4}$ Effect of ambient temperature on temperature difference between d 0 and 21 of the respective claw. 


\section{DISCUSSION}

Before claw trimming, the surface temperature of the lateral claws of the hind feet was significantly higher than that of the medial claws, whereas such a difference was not evident for the claws of the front feet. The mean $\Delta \mathrm{T}\left(\geq 0.25^{\circ} \mathrm{C}\right)$ in the hind feet showed a trend to be lower at $\mathrm{d} 21$ compared with $\mathrm{d} 0$, whereas we detected no such difference for $\Delta \mathrm{T}\left(\leq 0.13^{\circ} \mathrm{C}\right)$ in the front feet.

The interval between the 2 temperature measurements was chosen to be $21 \mathrm{~d}$ for the following reasons: (1) similar intervals of $2 \mathrm{wk}$ (van der Tol et al., 2002, 2004) and 3 wk (Distl et al., 1990) were chosen in studies comparing the load distribution pre- versus posttrimming; (2) the interval should be long enough to allow for a complete disappearance of the temperature elevation caused by the grinding of the horn at claw trimming; and (3) the cows were completely acquainted to the new situation of load redistribution and a stable situation was reached. We assumed that the effect of load redistribution was sustainable within at least 1 to 2 mo after trimming. Otherwise, the frequency of claw trimming in practice should be markedly increased. However, the temperature difference of partner claws of the hind feet might have been even smaller during the first days after trimming compared with that at $\mathrm{d} 21$.

Platz et al. (2008) reported that rubber mats allow the claws to sink to some depth (a few millimeters), thus reducing the impact load and mechanical pressure. The average contact pressure on the weight-bearing surface of the hind feet was found to be lesser on rubber mats than on concrete floor (Telezhenko et al., 2008). To the best of our knowledge, information on the effect of floor type on claw temperature of cattle has not been reported. It could be hypothesized that rubber mats provide greater temperature isolation than concrete floors. These potential influences must not, however, be considered in this study, because the flooring conditions did not change between paired measurements, and within-foot temperature differences rather than absolute values were taken into account.

The ambient temperature and infectious status of the foot were identified as external and internal factors, respectively, that significantly affected claw temperature. Environmental factors such as ambient temperature, dirt, direct sunlight, airflow, and humidity may affect the reliability of thermographic imaging (Bowers et al., 2009) due to adaptation of the peripheral perfusion and consecutive change of heat emitted from the skin surface. This is in agreement with Loughmiller et al. (2001) and Gloster et al. (2011), who found that foot temperature measured by IRT is largely affected by ambient temperature. In the current study, all thermographic measurements were done within the thermally neutral zone for lactating dairy cattle (Roenfeldt, 1998) and in closed barns without exposure to any direct sunlight or detectable airflow. Nevertheless, we found a significant effect of ambient temperature when d 0 and d 21 were compared. In this case, the chosen model corrected for this effect.

When temperatures of medial versus lateral claws at d 0 and d 21 were compared, a significant effect of ambient temperature was not present, as measurements were done at the same time (similar environmental conditions). Therefore, data were reported as temperature differences $(\Delta \mathrm{T})$ rather than as absolute values.

Infectious foot disorders had a significant effect on $\mathrm{S}_{\max }$ and $\mathrm{CB}_{\max }$ at $\mathrm{d} 0$, whereas this was not evident at d 21, except for $\mathrm{S}$ of the front feet. This is in agreement with the finding of Munsell (2004), who reported that, $5 \mathrm{~d}$ before foot trimming, cows with foot lesions had significantly higher $\mathrm{CB}_{\max }$ than feet without lesions, whereas $5 \mathrm{~d}$ after trimming, there was no difference of $\mathrm{CB}_{\max }$ between cows with and without lesions. We hypothesize that this is caused by the effective treatment of IFD in the course of foot trimming. However, further longitudinal studies are needed to monitor the immediate effect of treatment on foot temperature. Infectious foot disorders were diagnosed by 1 of 2 trained veterinarians according to existing clinical signs. We cannot completely exclude the possibility that some claws were erroneously misdiagnosed as healthy even though subclinical infection was present at the time of trimming (Alsaaod et al., 2014). False allocation of the respective claws to the nonlesion group instead of the IFD group would have been the consequence.

Hind and front feet were analyzed separately for 2 main reasons: (1) the prevalence of foot lesions of the hind feet was higher than that of the front feet, which corresponds well with the literature (Murray et al., 1996; Cramer et al., 2008), and (2) the pressure distributions of the claws and the lengths of the digital bones are different in the front and hind feet (van der Tol et al., 2002, 2004; Carvalho et al., 2006; Muggli et al., 2011). Equivocal information in the literature exists concerning the weight-bearing distribution between the claws of the front feet after functional claw trimming. Although no difference was found during static analysis (van der Tol et al., 2004), the load distribution on the lateral claws was higher at dynamic analysis (Schmid et al., 2009). In the current study, no temperature difference of the front claws was found at d 0 , and the temperature of the lateral claws was only slightly higher at $\mathrm{d} 21$.

The lateral claws of the hind feet are more often affected by mechanical claw lesions than any other claw (Russell et al., 1982; Toussaint Raven, 1989; Smits et 
al., 1992; Nikkhah et al., 2005). Paulus and Nuss (2002) and van Amstel and Shearer (2004) showed that the sole thickness of the lateral claws of the hind feet is lesser than that of the medial claws. In agreement with this, Nuss and Paulus (2006) reported that trimming of the hind feet might result in excessive thinning of the sole of the lateral claws. As the lateral claw bears more weight than its partner claw, wear of the lateral claw is faster (Vokey et al., 2001). This is compensated for by increased growth of claw horn (Nocek, 1997), which may be accomplished by an increased turnover rate of the cells of the corium, requiring an increased supply of blood and nutrients (Nikkhah et al., 2005). The mechanism regulating increased blood supply has, to the best of our knowledge, not yet been elucidated. In humans, hot spots identified by thermography occur at recognized sites of elevated weight bearing, indicating tissue injury or inflammation (Armstrong et al., 2007; Houghton et al., 2013). Therefore, increased localized pressure might lead to an increase in blood supply and consequently to an elevation of temperature at the areas of $\mathrm{CB}$ and $\mathrm{S}$.

Uneven distribution of load between claws has been identified as a biomechanical factor contributing to the development of claw lameness (Toussaint Raven, 1989). A recent study (Muggli et al., 2011) reported that the length of the paired digits is different, so that the overall length of the lateral digit, from the epiphyseal line of metatarsus III/IV to the tip of distal phalanx, is significantly greater in heifers and adult cows compared with the medial digit. The main principle of functional claw trimming is to reduce the maximal load on the lateral hind claws and to redistribute part of the pressure to the medial claw (van der Tol et al., 2004; Carvalho et al., 2006). Functional claw trimming in the cows in the current study was performed by professional trimmers who are offered continuing education courses yearly. Therefore, we can assume that these claw trimmers were able to deliver state-of-the-art trimming. In the current study, foot trimming was associated with a reduction (trend) of $\Delta \mathrm{T}$ of the hind feet, whereas such a difference was not evident in the front feet. This result is in line with the main principle of claw trimming and in agreement with van der Tol et al. (2004), who found that claw trimming affected weight bearing and pressure distributions on the hind claws. They reported that in the hind feet, the load of the lateral claws was reduced from $80 \%$ (pre-trimming) to $70 \%$ (2 wk posttrimming), whereas in the front feet, the load distribution was not significantly affected by claw trimming, although a greater increase of $\mathrm{CB}_{\max }$ occurred in the lateral claw compared with the medial claw.

Analysis of $\mathrm{CB}_{\max }$ and $\mathrm{S}_{\max }$ by IRT proved to be a useful technique to elucidate the effect of claw trim- ming on claw temperature. The results of this study demonstrated, for the first time, that a more balanced load of the hind claws, as achieved by functional claw trimming, was associated with a reduction of $\Delta \mathrm{T}$ between the partner claws. Further analyses are warranted to elucidate the potential benefit of IRT in cows kept in freestalls for objective, automated, and noninvasive assessment of the attempts to balance weight bearing between partner claws of the hind feet as a major goal of the professional activity of foot-trimmers.

\section{CONCLUSIONS}

We conclude that the effort to balance the weight bearing of the hind feet by routine claw trimming is accompanied by a measurable reduction of $\Delta \mathrm{T}$ between the paired hind claws. Infrared thermography may be a useful tool for noninvasive assessment of the quality of the functional claw-trimming activity.

\section{ACKNOWLEDGMENTS}

This study was generously supported by a grant of the Fondation Sur-La-Croix (Basel, Switzerland). We thank the Institute of Virology and Immunology (IVI, Mittelhäusern, Switzerland) for use of the IRT camera for this project.

\section{REFERENCES}

Alsaaod, M., C. Syring, J. Dietrich, M. G. Doherr, T. Gujan, and A. Steiner. 2014. A field trial of infrared thermography as a noninvasive diagnostic tool for early detection of digital dermatitis in dairy cows. Vet. J. 199:281-285.

Armstrong, D. G., K. Holtz-Neiderer, C. Wendel, M. J. Mohler, H. R. Kimbriel, and L. A. Lavery. 2007. Skin temperature monitoring reduces the risk for diabetic foot ulceration in high-risk patients. Am. J. Med. 120:1042-1046.

Bicalho, R. C., and G. Oikonomou. 2013. Control and prevention of lameness associated with claw lesions in dairy cows. Livest. Sci. 156:96-105.

Blowey, R. W., P. Ossent, C. L. Watson, V. Hedges, L. E. Green, and A. J. Packington. 2000. Possible distinction between sole ulcers and heel ulcers as a cause of bovine lameness. Vet. Rec. 147:110-112.

Bowers, S., S. Gandy, B. Anderson, P. Ryan, and S. Willard. 2009. Assessment of pregnancy in the late-gestation mare using digital infrared thermography. Theriogenology 72:372-377.

Carvalho, V., I. Naas, R. Bucklin, J. Shearer, K. Shearer, V. Massafera, and S. Souza. 2006. Effects of trimming on dairy cattle hoof weight bearing surfaces and pressure distributions. Braz. J. Vet. Res. Anim. Sci. 43:518-525.

Chan, A. W., I. A. MacFarlane, and D. R. Bowsher. 1991. Contact thermography of painful diabetic neuropathic foot. Diabetes Care 14:918-922.

Collick, D. W., W. R. Ward, and H. Dobson. 1989. Associations between types of lameness and fertility. Vet. Rec. 125:103-106.

Cramer, G., K. D. Lissemore, C. L. Guard, K. E. Leslie, and D. F. Kelton. 2008. Herd- and cow-level prevalence of foot lesions in Ontario dairy cattle. J. Dairy Sci. 91:3888-3895.

Distl, O., H. Krausslich, A. Mair, C. Spielmann, and W. Diebschlag. 1990. Computer-aided analysis of pressure distributions under- 
neath claws of cattle. Deutsch. Tierarztl. Wochenschr. 97:474479.

Döpfer, D., A. Koopmans, F. A. Meijer, I. Szakall, Y. H. Schukken W. Klee, R. B. Bosma, J. L. Cornelisse, A. J. van Asten, and A. A. ter Huurne. 1997. Histological and bacteriological evaluation of digital dermatitis in cattle, with special reference to spirochaetes and Campylobacter faecalis. Vet. Rec. 140:620-623.

Eddy, A. L., L. M. Van Hoogmoed, and J. R. Snyder. 2001. The role of thermography in the management of equine lameness. Vet. J. 162:172-181

Gloster, J., K. Ebert, S. Gubbins, J. Bashiruddin, and D. J. Paton. 2011. Normal variation in thermal radiated temperature in cattle: Implications for foot-and-mouth disease detection. BMC Vet. Res. $7: 73$.

Goller, H., D. W. Lewis, and R. E. McLaughlin. 1971. Thermographic studies of human skin subjected to localized pressure. Am. J. Roentg. Rad. Therap. Nuc. Med. 113:749-754.

Houghton, V. J., M. B. Virginia, and D. C. Chant. 2013. Is an increase in skin temperature predictive of neuropathic foot ulceration in people with diabetes? A systematic review and meta-analysis. J. Foot Ankle Res. 6:31.

Kofler, J. 2013. Computerised claw trimming database programs as the basis for monitoring hoof health in dairy herds. Vet. J. 198:358-361

Lischer, C., A. Steiner, H. Geyer, K. Friedli, P. Ossent, and K. Nuss. 2014. Klauenpflege (Handbuch zur Klauenpflege beim Rind). 4th ed. rev. Edition lmz, Zollikofen, Switzerland.

Loughmiller, J. A., M. F. Spire, S. S. Dritz, B. W. Fenwick, M. H. Hosni, and S. B. Hogge. 2001. Relationship between mean body surface temperature measured by use of infrared thermography and ambient temperature in clinically normal pigs and pigs inoculated with Actinobacillus pleuropneumoniae. Am. J. Vet. Res. 62:676-681.

Manske, T., J. Hultgren, and C. Bergsten. 2002. The effect of claw trimming on the hoof health of Swedish dairy cattle. Prev. Vet. Med. 54:113-129.

Meyer, S. W., M. A. Weishaupt, and K. A. Nuss. 2007. Gait pattern of heifers before and after claw trimming: A high-speed cinematographic study on a treadmill. J. Dairy Sci. 90:670-676.

Muggli, E., C. Sauter-Louis, U. Braun, and K. Nuss. 2011. Length asymmetry of the bovine digits. Vet. J. 188:295-300.

Munsell, B. 2004. The use of infrared thermography to determine surface temperature of the coronary band of dairy cows as a tool for lameness detection. PhD Thesis. Michigan State University, East Lansing.

Murray, R. D., D. Y. Downham, M. J. Clarkson, W. B. Faull, J. W Hughes, F. J. Manson, J. B. Merritt, W. B. Russell, J. E. Sutherst, and W. R. Ward. 1996. Epidemiology of lameness in dairy cattle: Description and analysis of foot lesions. Vet. Rec. 138:586-591.

Nacambo, S., M. Hässig, C. Lischer, and K. Nuss. 2007. Difference in the length of the medial and lateral metacarpal and metatarsal condyles in calves and cows - A post-mortem study. Anat. Histol. Embryol. 36:408-412.

Nikkhah, A., J. C. Plaizier, M. S. Einarson, R. J. Berry, S. L. Scott, and A. D. Kennedy. 2005. Short communication: Infrared thermography and visual examination of hooves of dairy cows in two stages of lactation. J. Dairy Sci. 88:2749-2753.

Nocek, J. E. 1997. Bovine acidosis: Implications on laminitis. J. Dairy Sci. 80:1005-1028.

Nuss, K., and N. Paulus. 2006. Measurements of claw dimensions in cows before and after functional trimming: A post-mortem study. Vet. J. 172:284-292.

Paulus, N., and K. Nuss. 2002. Claw measurements at defined sole thickness. Pages 428-430 in Proc. 12th Int. Symp. Lameness Rumin., Orlando, Florida.
Phillips, C. J., P. C. Chiy, M. J. Bucktrout, S. M. Collins, C. J. Gasson, A. C. Jenkins, and M. J. Paranhos da Costa. 2000. Frictional properties of cattle hooves and their conformation after trimming. Vet. Rec. 146:607-609.

Platz, S., F. Ahrens, E. Bahrs, S. Nuske, and M. H. Erhard. 2007. Association between floor type and behaviour, skin lesions, and claw dimensions in group-housed fattening bulls. Prev. Vet. Med. 80:209-221.

Platz, S., F. Ahrens, J. Bendel, H. H. D. Meyer, and M. H. Erhard. 2008. What happens with cow behavior when replacing concrete slatted floor by rubber coating: A case study. J. Dairy Sci. 91:999-1004.

Pringle, J., C. Uystepruyst, T. Art, and P. Lekeux. 1998. Near infrared spectroscopy of the normal bovine claw. Vet. J. 156:155-158.

Räber, M., J. Lischer Ch, H. Geyer, and P. Ossent. 2004. The bovine digital cushion-A descriptive anatomical study. Vet. J. 167:258 264.

Roenfeldt, R. 1998. You can't afford to ignore heat stress. Dairy Herd Management 35:6-12.

Russell, A. M. G. J. Rowlands, S. R. Shaw, and A. D. Weaver. 1982 Survey of lameness in British dairy cattle. Vet. Rec. 111:155-160.

Rusterholz, A. 1920. Das spezifisch-traumatische Klauensohlengeschwür des Rindes. Schweiz. Arch. Tierheilk. 62:421-466.

Schmid, T., M. A. Weishaupt, S. W. Meyer, N. Waldern, K. Peinen, and K. Nuss. 2009. High-speed cinematographic evaluation of clawground contact pattern of lactating cows. Vet. J. 181:151-157.

Shearer, J. K., and S. R. van Amstel. 2001. Functional and corrective claw trimming. Vet. Clin. North Am. Food Anim. Pract. $17: 53-72$.

Smits, M. C. J., K. Frankena, J. H. M. Metz, and J. P. T. M. Noordhuizen. 1992. Prevalence of Digital Disorders in Zero-Grazing Dairy-Cows. Livest. Prod. Sci. 32:231-244.

Stewart, M., J. R. Webster, G. A. Verkerk, A. L. Schaefer, J. J. Colyn, and K. J. Stafford. 2007. Non-invasive measurement of stress in dairy cows using infrared thermography. Physiol. Behav. 92:520525.

Telezhenko, E., C. Bergsten, M. Magnusson, M. Ventorp, and C. Nilsson. 2008. Effect of different flooring systems on weight and pressure distribution on claws of dairy cows. J. Dairy Sci. 91:18741884.

Toussaint Raven, E. 1989. Cattle Footcare and Claw Trimming. Farming Press, Ipswich, UK.

van Amstel, S. R., and J. K. Shearer. 2006. Review of Pododermatitis circumscripta (ulceration of the sole) in dairy cows. J. Vet. Intern. Med. 20:805-811.

van der Tol, P. P., J. H. Metz, E. N. Noordhuizen-Stassen, W. Back, C. R. Braam, and W. A. Weijs. 2002. The pressure distribution under the bovine claw during square standing on a flat substrate. J. Dairy Sci. 85:1476-1481.

van der Tol, P. P., S. S. van der Beek, J. H. Metz, E. N. NoordhuizenStassen, W. Back, C. R. Braam, and W. A. Weijs. 2004. The effect of preventive trimming on weight bearing and force balance on the claws of dairy cattle. J. Dairy Sci. 87:1732-1738.

Van Hoogmoed, L. M., and J. R. Snyder. 2002. Use of infrared thermography to detect injections and palmar digital neurectomy in horses. Vet. J. 164:129-141.

Vokey, F. J., C. L. Guard, H. N. Erb, and D. M. Galton. 2001. Effects of alley and stall surfaces on indices of claw and leg health in dairy cattle housed in a free-stall barn. J. Dairy Sci. 84:2686-2699.

Wilhelm, K. 2010. Die subklinische Klauenrehe beim Milchrind-Thermographische Untersuchungen der Klaue und Beziehungen zum Energiestoffwechsel. DVM Thesis. University of Leipzig, Germany. 